\title{
ANALISIS REGRESI TERSEGMEN MENGGUNAKAN METODE GAUSS-NEWTON
}

\author{
PUTRI PERMATHASARI \\ Program Studi Matematika, \\ Fakultas Matematika dan Ilmu Pengetahuan Alam, Universitas Andalas, \\ Kampus UNAND Limau Manis Padang, Indonesia, \\ putripermathasari@yahoo.co.id
}

\begin{abstract}
Abstrak. Analisis regresi adalah metode statistika yang digunakan untuk membentuk model hubungan antara variabel bebas dengan variabel tak bebas. Analisis ini bisa dilakukan terhadap seluruh data ataupun membagi nilai-nilai variabel bebas menjadi beberapa bagian (segmen) kemudian menerapkan analisis regresi pada setiap segmen, yang dikenal dengan analisis regresi linier tersegmen. Regresi linier tersegmen adalah metode dalam analisis regresi yang membagi variabel bebas menjadi beberapa segmen berdasarkan nilai tertentu yang disebut breakpoint. Metode yang digunakan untuk mengestimasi nilai-nilai parameter regresi linier tersegmen dan nilai breakpoint optimum yaitu metode Gauss-Newton atau disebut linierisasi menggunakan deret Taylor orde pertama. Data ilustrasi yang digunakan dalam penerapan analisis regresi tersegmen ini adalah data sekunder US Department of Energy, 1990 Fuel Economy. Data dapat diakses melalui (http:/www.seattlecentral.edu/qelp/sets/036/036.html.). Pada data ini diteliti hubungan antara ukuran mesin mobil (liter) dengan jarak tempuh jalan raya (mpg).
\end{abstract}

Kata Kunci: Analisis regresi tersegmen, breakpoint, Gauss-Newton

\section{Pendahuluan}

Istilah regresi diperkenalkan oleh Francis Galton pada tahun 1885. Analisis regresi adalah metode statistika yang digunakan untuk membentuk model hubungan antara variabel bebas dengan variabel tak bebas. Berdasarkan sifatnya, analisis regresi dibagi atas regresi linier dan regresi non linier. Analisis regresi linier digunakan jika hubungan antara variabel bebas dengan variabel tak bebas bersifat linier dalam parameter. Sebaliknya analisis regresi non linier digunakan jika hubungan kedua variabel bersifat non linier dalam parameter. Analisis regresi linier dapat dibedakan menjadi dua yaitu analisis regresi linier sederhana dan analisis regresi linier berganda [1].

Ketika meneliti suatu hubungan antara variabel tak bebas dan variabel bebas, mungkin saja terjadi hubungan non-linier. Model regresi linier sederhana tidak dapat menggambarkan data yang memiliki hubungan non-linier karena model regresi linier sederhana mengabaikan perubahan trend. Salah satu model regresi yang dapat digunakan untuk mengatasi ketidaklinieran hubungan antara variabel tak bebas dan variabel bebas adalah regresi tersegmen. Regresi tersegmen merupakan suatu metode dalam analisis regresi yang membagi variabel bebas menjadi beberapa segmen berdasarkan nilai tertentu yang disebut breakpoint, di mana pada setiap 
segmen data terdapat model regresi linier. Metode yang digunakan untuk mengestimasi nilai-nilai parameter regresi linier tersegmen dan nilai breakpoint optimum yaitu metode Gauss-Newton atau disebut linierisasi menggunakan deret Taylor orde pertama. Sifat tersegmen inilah yang memberikan fleksibilitas yang lebih baik dari pada model regresi linier sederhana.

Tujuan penulisan tulisan ini adalah untuk mengestimasi nilai-nilai parameter regresi sehingga diperoleh model regresi linier dua segmen, serta mengestimasi breakpoint optimum menggunakan metode Gauss-Newton dan menguji signifikasinya.

\section{Tinjauan Pustaka}

\subsection{Diagram Pencar}

Diagram pencar digunakan untuk mengidentifikasi hubungan dua variabel yang dinyatakan dalam sumbu-X dan sumbu-Y, sehingga diketahui pola hubungan antara kedua variabel. Pada Gambar 2.1 disajikan tiga pola yang mungkin terbentuk pada diagram pencar.

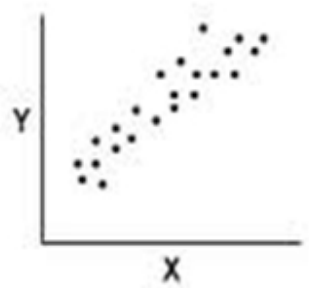

a

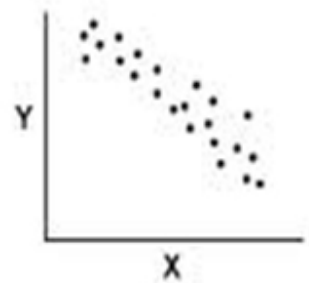

b

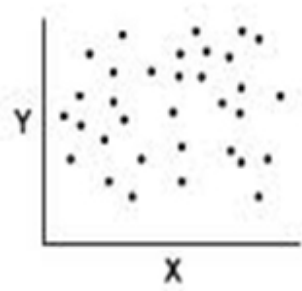

C

Gambar 2.1. Tipe Diagram Pencar

\subsection{Analisis Regresi Linier Sederhana}

Regresi linier sederhana adalah persamaan regresi yang menggambarkan hubungan antara satu variabel bebas dengan satu variabel tak bebas. Berikut diberikan suatu model regresi linier sederhana.

$$
Y_{i}=\beta_{0}+\beta_{1} x+\varepsilon_{i}, \quad i=1,2, \cdots, n,
$$

di mana $Y_{i}$ adalah variabel tak bebas, $X_{i}$ adalah variabel bebas, $\beta_{0}$ dan $\beta_{1}$ adalah parameter regresi, dan $\varepsilon_{i}$ adalah komponen galat.

\subsection{Metode Kuadrat Terkecil dalam Kasus Regresi Linier Sederhana}

Metode kuadrat terkecil adalah metode yang meminimumkan Jumlah Kuadrat Sisaan (JKS) yaitu $\sum e_{i}^{2}$ minimum. Caranya yaitu dengan melakukan penurunan parsial $\sum e_{i}^{2}$ terhadap setiap komponen vektor $\beta$ dan menyamakannya dengan 0 . 
Maka diperoleh pendugaan parameter regresi dengan metode kuadrat terkecil sebagai berikut.

$$
\hat{\beta}=\left(X^{T} X\right)^{-1}\left(X^{T} Y\right)
$$

\subsection{Pengujian Parameter}

Pengujian terhadap parameter regresi dilakukan dengan analisis varians (ANOVA) yang memecah keragaman total menjadi komponen regresi dan sisaan. Analisis varians dilakukan untuk menguji apakah model regresi cocok terhadap data [1].

Bentuk pengujian hipotesis yang digunakan dalam uji ini adalah :

$H_{0}: \beta_{1}=0$ (variabel bebas tidak berpengaruh terhadap variabel tak bebas) $H_{1}: \beta_{1} \neq 0$ (variabel bebas berpengaruh terhadap variabel tak bebas)

\begin{tabular}{|c|c|c|c|c|c|}
\hline Sumber & Derajat & Jumlah Kuadrat & Kuadrat & & \\
\hline Variansi & $\begin{array}{l}\text { Bebas } \\
\text { (db) }\end{array}$ & $(\mathrm{JK})$ & $\begin{array}{l}\text { Tengah } \\
(\mathrm{KT})\end{array}$ & $F_{\text {hitung }}$ & $F_{\text {tabel }}$ \\
\hline Regresi & $d b r=1$ & $J K R=\sum_{\mathrm{j}=1}^{\mathrm{n}}\left(\overline{\mathrm{Y}}_{\mathrm{j}}-\overline{\mathrm{Y}}\right)^{2}$ & $K T R=J K R$ & $\frac{K T R}{K T S}$ & $F_{1 ; n-2 ; a}$ \\
\hline Sisaan & $d b s=n-2$ & $J K S=\sum_{\mathrm{j}=1}^{\mathrm{n}}\left(\mathrm{Y}_{\mathrm{i}}-\overline{\mathrm{Y}}_{\mathrm{j}}\right)^{2}$ & $K T S=\frac{J K S}{n-2}$ & & \\
\hline Total & $d b t=n-1$ & $J K T=\sum_{\mathrm{j}=1}^{\mathrm{n}}\left(\mathrm{Y}_{\mathrm{j}}-\overline{\mathrm{Y}}\right)^{2}$ & & & \\
\hline
\end{tabular}

Gambar 2.2. Tabel Analisis Varians Regresi linier Sederhana

\subsection{Koefisien Determinasi}

$$
R^{2}=\frac{\sum\left(\hat{Y}_{i}-\bar{Y}\right)^{2}}{\sum\left(\hat{Y}_{i}-\bar{Y}\right)^{2}}=\frac{J K R}{J K S}=1-\frac{J K S}{J K T} .
$$

$R^{2}$ sering disebut sebagai perbandingan keragaman variabel tak bebas yang dijelaskan oleh variabel bebas. Karena $0 \leq J K S \leq J K T$ maka berlaku $0 \leq R^{2} \leq 1$.

\subsection{Regresi Non Linier}

Dalam analisis regresi, hubungan antara variabel tak bebas dengan variabel bebasnya dinyatakan dalam suatu model yang biasanya diistilahkan sebagai model 
regresi. Model tersebut menghubungkan variabel bebas dan tak bebas melalui suatu parameter yang dinamakan sebagai parameter regresi dan biasanya dinotasikan dengan $\beta$, bila model tersebut tidak linier dalam parameter maka model tersebut dinamakan sebagai model non linier [1].

Secara umum model non linier adalah sebagai berikut :

$$
Y_{i}=f\left(X_{i}, \beta\right)+\varepsilon_{i}
$$

di mana $Y_{i}$ adalah variabel tak bebas, $X_{i}$ adalah variabel bebas, $\beta$ adalah parameter regresi dan $\varepsilon_{i}$ adalah komponen galat.

\section{Pembahasan}

\subsection{Analisis Regresi Linier Tersegmen}

Model regresi linier tersegmen adalah model regresi yang terdiri dari dua segmen yang bersifat linier. Model ini digunakan apabila terdapat indikasi perubahan nilai parameter setelah nilai tertentu pada variabel bebas.Pada metode ini, garis regresi tidak lagi disajikan dalam satu garis linier, melainkan disajikan dalam dua garis linier yang bertemu pada suatu titik, yaitu titik $X_{s i}=c$. Dengan demikian, terdapat dua model regresi berikut.

$$
\begin{array}{ll}
Y_{1 i}=\beta_{01}+\beta_{11} X_{1 i} & X_{1 i} \leqslant c \\
Y_{2 i}=\beta_{02}+\beta_{12} X_{2 i} & X_{2 i}>c
\end{array}
$$

Pada saat titik $X_{s i}=c$, dengan $s=1,2$, diperoleh bentuk lain dari model regresi linier tersegnen, yaitu

$$
Y_{1 i}=\beta_{01}+\beta_{11} X_{1 i}, X_{1 i} \leqslant c, Y_{2 i}=\left\{\beta_{01}+c\left(\beta_{11}-\beta_{12}\right)\right\}+\beta_{12} X_{2 i}, X_{2 i}>c .
$$

Dengan menggunakan metode kuadrat terkecil diperoleh nilai dugaan untuk c yaitu

$$
\hat{c}=-\left(\frac{\beta_{01}-\beta_{02}}{\beta_{11}-\beta_{12}}\right) .
$$

\subsection{Estimasi Model Regresi Linier Dua Segmen dengan Metode Gauss-Newton}

Metode Gauss-Newton merupakan algoritma untuk meminimumkan jumlah kuadrat sisaan. Konsep yang mendasari teknik tersebut adalah uraian deret Taylor yang digunakan untuk menyatakan persamaan non-linier semula dalam suatu bentuk hampiran yang linier.Untuk melakukan iterasi Gauss Newton, pertama-tama dilakukan pendekatan terhadap fungsi $f(X, \beta)$ menggunakan deret Taylor di sekitar initial value $\beta^{(0)}$ yang nilainya ditentukan.

Pendekatan terhadap fungsi $f(X, \beta)$ di sekitar $\beta^{(0)}$ dengan menggunakan deret Taylor orde pertama dapat dituliskan sebagai berikut.

$$
\begin{aligned}
f(X, \beta) & =f\left(X, \beta^{(0)}\right)+\left.\frac{\partial f(x, \beta)}{\partial \beta^{\prime}}\right|_{\beta^{(0)}}\left(\beta-\beta^{(0)}\right) \\
& =f\left(X, \beta^{(0)}\right)+\left.\frac{\partial f(x, \beta)}{\partial \beta^{\prime}}\right|_{\beta^{(0)}} \beta-\left.\frac{\partial f(x, \beta)}{\partial \beta^{\prime}}\right|_{\beta^{(0)}} \beta^{(0)} .
\end{aligned}
$$


Misalkan $\left.\frac{\partial f(x, \beta)}{\partial \beta^{\prime}}\right|_{\beta^{(0)}}=z\left(\beta^{(0)}\right)$, sehingga diperoleh

$$
Y-f\left(X, \beta^{(0)}\right)+z\left(\beta^{(0)}\right) \beta^{(0)}=z\left(\beta^{(0)}\right) \beta+e .
$$

Jika didefinisikan

$$
\bar{Y}\left(\beta^{(0)}\right)=Y-f\left(X, \beta^{(0)}\right)+z\left(\beta^{(0)}\right) \beta^{(0)},
$$

terlihat bahwa persamaan diatas adalah persamaan yang linier dalam parameter $\beta$, sehingga dengan menggunakan metode ordinary least square diperoleh estimasi $\beta^{(1)}$ berikut.

$$
\beta^{(1)}=\left(z\left(\beta^{(0)}\right)^{T} z\left(\beta^{(0)}\right)\right)^{-1} z\left(\beta^{(0)}\right)^{T} \bar{Y}\left(\beta^{(n)}\right) .
$$

Persamaan berikut merupakan persamaan Gauss-Newton dengan $t$ menunjukkan banyaknya iterasi

$$
\beta^{(t+1)}=\beta^{(t)}+\left(z\left(\beta^{(n)}\right)^{T} z\left(\beta^{(n)}\right)\right)^{-1} z\left(\beta^{(n)}\right)^{T}\left(Y_{i}-f\left(X, \beta^{(t)}\right)\right) .
$$

\subsection{Analisis Varians Regresi Linier Tersegmen}

Analisis varians (ANOVA) regresi linier tersegmen merupakan pengembangan dari analisis varians regresi linier sederhana. Pada tahap ini, terdapat penguraian jumlah kuadrat total atas kedua komponennya yaitu jumlah kuadrat regresi dan jumlah kuadrat sisaan.

\begin{tabular}{|c|c|c|c|c|c|}
\hline $\begin{array}{c}\text { Sumber } \\
\text { Variansi }\end{array}$ & $\begin{array}{c}\text { Derajat } \\
\text { bebas (db) }\end{array}$ & $\begin{array}{c}\text { Jumlah } \\
\text { Kuadrat } \\
(\mathrm{JK})\end{array}$ & $\begin{array}{c}\text { Kuadrat } \\
\text { Tengah } \\
(\mathrm{KT})\end{array}$ & $\mathrm{F}_{\text {hitung }}$ & $\mathrm{F}_{\text {tabel }}$ \\
\hline Regresi & 3 & $J K R_{p}$ & $K T R_{p}=\frac{J K R_{p}}{3}$ & $\frac{K T R_{p}}{K T S_{p}}$ & $\mathrm{~F}_{3 ; \mathrm{n}-4 ; \alpha}$ \\
\hline Sisaan & $n-4$ & $J K S_{p}$ & $K T S_{p}=\frac{J K S_{p}}{n-4}$ & & \\
\hline Total & $n-1$ & $J K T_{p}$ & & & \\
\hline
\end{tabular}

Gambar 3.1. Tabel Analisis Varians Regresi linier Tersegmen

\subsection{Ilustrasi Kasus}

Data yang digunakan dalam penelitian ini adalah data sekunder US Department of Energy, 1990 Fuel Economy. Data dapat diakses melalui http:/www.seattlecentral.edu/qelp/sets/036/036.html. Dengan Variabel tak bebas yang digunakan dalam penelitian ini adalah Highway Mileage (mpg) yang berarti jarak tempuh jalan raya, dalam satuan (mpg) dan Variabel bebas yang digunakan dalam penelitian ini adalah Engine Size (liters) yang berarti ukuran mesin, dalam satuan (liter). 


\subsubsection{Pembahasan Ilustrasi Kasus}

\section{Hasil Analisis Regresi Linier Sederhana}

Setelah dilakukan analisis data pengaruh ukuran mesin (liter) terhadapa jarak tempuh jalan raya diperoleh model regresi linier sederhana $\hat{Y}=39.97798-3.77083 X$ dengan koefisien korelasi $R^{2}=0.621$.

Pendugaan Nilai Awal $\hat{c}$ dan Mengestimasi Koefisien Regresi Linier Dua Segmen Menggunakan MKT

Untuk menduga nilai awal $\hat{c}$ dibuat diagram pencar antara variabel bebas dan variabel respon.

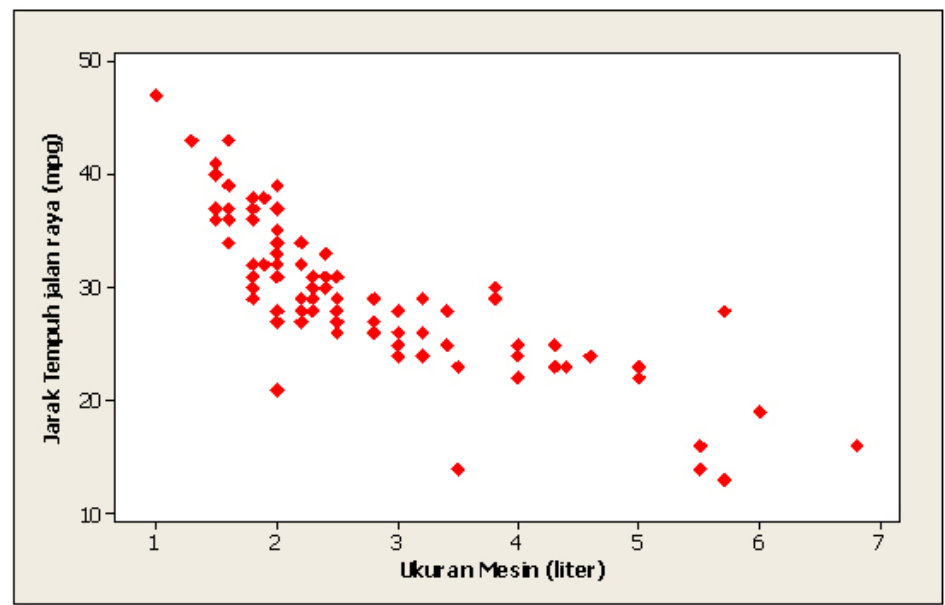

Gambar 3.2. Diagram Pencar

Berdasarkan diagram pencar tersebut nilai dugaan awal $\hat{c}=2.3$ nilai duagaan tersebut berada pada $i=63$, selanjutnya dibentuk dua model regresi linier dari data yang telah terbagi dua pada $X_{i}=2.3$. Dua persamaan regresi tersebut adalah

$$
\hat{Y}_{i}= \begin{cases}57.7755-12.7101 X & ; X_{i} \leq 2.3 \\ 35.0967-2.6401 X \quad ; X_{i}>2.3\end{cases}
$$

Nilai dugaan awal $\hat{c}=2.3$ dan nilai-nilai koefisien regresi di atas kemudian digunakan sebagai nilai awal $\hat{\beta}^{(0)}$ pada metode iterasi Gauss-Newton untuk mengestimasi nilai $\hat{c}_{\text {optimum }}=2.3$ dan nilai-nilai parameter regresi linier tersegmen yang konvergen pada iterasi ke-3.

Persamaan regresi linier piecewise dua segmen jika dituliskan pada masingmasing segmen adalah :

$$
\hat{Y}_{i}= \begin{cases}58.4326-13.0934 X & ; X_{i} \leq 2.2302 \\ 35.1391-2.6488 X & ; X_{i}>2.2302\end{cases}
$$

Hasil iterasi Gauss-Newton ditunjukkan pada Gambar 3.3. 


\begin{tabular}{|c|c|c|c|c|c|c|}
\hline Iterasi & $\hat{\beta}_{01}$ & $\hat{\beta}_{11}$ & $\hat{\beta}_{01}$ & $\hat{\beta}_{12}$ & $\hat{c}$ & JKS \\
\hline 0 & 57.7755 & -12.7101 & -2.6401 & -2.6401 & 2.3000 & 1341 \\
1 & 57.7755 & -12.7101 & -2.6401 & -2.6401 & 2.2521 & 1323.3 \\
2 & 58.4326 & -13.0935 & -2.6488 & -2.6488 & 2.2294 & 1322.5 \\
3 & 58.4326 & -13.0935 & -2.6488 & -2.6488 & 2.2302 & 1322.5 \\
\hline
\end{tabular}

Gambar 3.3. Hasil Iterasi Gauss-Newton $\hat{c}=2.3$

\section{Kesimpulan}

Pada hasil regresi linier dua segmen pada data ilustrasi diperoleh $K T S=10.3324$ dan $R^{2}=0.74$, sedangkan pada analisis regresi linier sederhana diperoleh $K T S=$ 14.86587 dan $R^{2}=0.621$. Berdasarkan perbandingan nilai KTS dan R2 pada kasus tersebut, model regresi linier tersegmen merupakan model terbaik dibandingkan model regresi linier sederhana karena menghasilkan nilai KTS yang lebih kecil dan $R^{2}$ yang lebih besar.

\section{Ucapan Terima kasih}

Penulis mengucapkan terima kasih kepada Bapak Dr. Dodi Devianto, Ibu Izzati Rahmi HG, M.Si, Ibu Hazmira Yozza, M.Si, Ibu Nova Noliza Bakar, M.Si, Ibu Arrival Rince Putri, MT, M.Si yang telah memberikan masukan dan saran sehingga paper ini dapat diselesaikan dengan baik.

\section{Daftar Pustaka}

[1] Draper, N dan Smith, H. 1992. Analisis Regresi Terapan. Edisi ke-2. Gramedia. Jakarta.

[2] Gujarati, D. 2003 Ekonometrika Dasar. Zain, S, terjemahan. Erlangga. Jakarta. Terjemahan dari: Basic Econometrics.

[3] Ryan, S.E dan Porth, L.S. 2007. A Tutorial on The Piecewise Regression Approach Applied to Bedload Transport Data.. Rocky Mountain Research Station. Amerika Serikat.

[4] Sembiring, R.K. 1995. Analisis Regresi. ITB. Bandung.

[5] Syilfi. 2012. Analisis Regresi Linier Piecewise Dua Segmen.http://ejournals1.undip.ac.id/index.php/gaussian [diakses pada 20 Desember 2012]. 